\title{
Index of Refraction of Magnesium Oxide
}

\author{
Robert E. Stephens and Irving H. Malitson
}

\begin{abstract}
The index of refraction of magnesium oxide crystal has been measured for wavelengths from 0.36 to 5.35 microns. In the visible region, measurements were made at three temperatures, close to $20^{\circ}, 30^{\circ}$, and $40^{\circ} \mathrm{C}$. Thermal coefficients were computed for this range of temperatures for nine wavelengths.
\end{abstract}

\section{Introduction}

In 1935, shortly after moderate sized artificially grown crystals of magnesium oxide became available, two papers were published dealing with the optical properties of this material. ${ }^{12}$

Strong and Brice measured the index of refraction of two prisms, cut from the same crystal, by photographic and visual means over the range from 2536 to 7065 A. Barnes, Brattain, and Seitz investigated the transmittance and reflectance of this material in the infrared region from approximately 1 to approximately $30 \mu$. They published a curve showing the index of refraction as calculated by means of the Fresnel reflection equations from the measured reflectance.

Some time ago two small prisms of magnesium oxide crystals of excellent optical quality were sent to the National Bureau of Standards by Elias Burstein of the Naval Research Laboratory for measurements of the index of refraction and the thermal coefficients of the index of refraction. These prisms, although rather small, were of high optical quality and entirely adequate for precision measurements of index in the visible region of the spectrum.

Because of the high sensitivity of the lead sulfide photoconducting cell in the region from about 0.3 to about $2.6 \mu$, it was found practicable to measure the index of refraction for several ultraviolet and infrared lines of the mercury and cadmium spectra with good accuracy. Beyond $2.6 \mu$ it was possible, by using wide slits and a Golay pneumatic detector, to get data of fair accuracy at the wavelengths of several absorption bands of polystyrene and carbon dioxide. Due to the limitations of the apparatus, the range of the measurements was from $0.36117 \mu$ (cadmium) to $5.35 \mu$ (polystyrene). According to the results referred to in footnotes 1 and 2 , magnesium oxide is usefully transparent from 0.2200 to $9 \mu$.

\section{Measurements in the Visual Range}

The index of refraction in the visible range was measured by means of a precision spectrometer by the minimum-deviation method. This was done at three temperatures near $20^{\circ}, 30^{\circ}$, and $40^{\circ} \mathrm{C}$ for each of nine wavelengths, which, with their emitting elements, are listed in table 1.

1 John Strong and R. T. Brice, Optical properties of magnesium oxide, J. Opt. Soc. Am. 25, 207 (1935)

${ }_{2}$ Barnes, Brattain, and Seitz, On the structure and interpretation of the infrared absorption spectra of erystals, Phys. Rev., 2d series, 48, 582 (1935).
TABLE 1. S pectrum lines used for index measurements

\begin{tabular}{|c|c|c|}
\hline Designation & Source & Wavelength \\
\hline $\begin{array}{l}\mathrm{A}^{\prime} \text { mean } \\
\mathrm{C} \\
\mathrm{D} \text { mean } \\
\mathrm{e}- \\
\mathrm{F}- \\
\mathrm{g} \\
\mathrm{h}\end{array}$ & 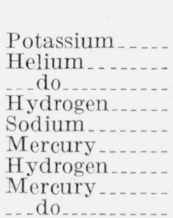 & $\begin{array}{c}A \\
7678.58 \\
7065.20 \\
6668.15 \\
6562.8 \\
5892.62 \\
5460.74 \\
4861.33 \\
4358.35 \\
4046.56\end{array}$ \\
\hline
\end{tabular}

By differencing all the observed indexes and the observed temperatures, thermal coefficients of index were computed for the ranges $20^{\circ}$ to $30^{\circ} \mathrm{C}$ and $30^{\circ}$ to $40^{\circ} \mathrm{C}$. These coefficients were averaged to obtain the coefficients for $30^{\circ} \mathrm{C}$. The coefficients for $30^{\circ} \mathrm{C}$ were plotted as a function of wavelength and smoothed values were read from a curve. Then, assuming linearity of the coefficients over the temperature range, the thermal coefficients of index were computed for $20^{\circ}, 25^{\circ}, 30^{\circ}, 35^{\circ}$, and $40^{\circ} \mathrm{C}$ at each of the wavelengths. These values are presented in table 2 .

TABLE 2. Thermal coefficients of index of refraction of magnesium oxide, $\Delta n \times 10^{6} /{ }^{\circ} \mathrm{C}$

\begin{tabular}{|c|c|c|c|c|c|}
\hline Wavelength & $20^{\circ} \mathrm{C}$ & $25^{\circ} \mathrm{C}$ & $30^{\circ} \mathrm{C}$ & $35^{\circ} \mathrm{C}$ & $40^{\circ} \mathrm{C}$ \\
\hline$A$ & & & 13.8 & 13.9 & 140 \\
\hline 7065 & $\begin{array}{l}13.0 \\
14.1\end{array}$ & $\begin{array}{l}\text { 13. } \\
14.2\end{array}$ & $\begin{array}{l}14.8 \\
14.3\end{array}$ & 14. 4 & 14.5 \\
\hline 6678 & 14.4 & 14.5 & 14.6 & 14.7 & 14.8 \\
\hline 6563 & 14.5 & 14. 6 & 14. 7 & 14.8 & 14.9 \\
\hline 5893 & 15.3 & 15.4 & 15.5 & 15. 6 & 15.7 \\
\hline 5461 & 15.9 & 16. 0 & 16.1 & 16.2 & 16.3 \\
\hline 4861 & 16.9 & 17. 0 & 17.1 & 17.2 & 17.3 \\
\hline 4358 & 18.0 & 18.1 & 18.2 & 18.3 & 18.4 \\
\hline 4047 & 18.9 & 19.0 & 19.1 & 19.2 & 19.3 \\
\hline
\end{tabular}

By the use of the table of coefficients, small corrections in index were made to all observed values of index, so that the corrected values correspond to exact temperatures of $20^{\circ}, 30^{\circ}$, and $40^{\circ} \mathrm{C}$. The corrected observed indexes, averaged for the two prisms, are listed in table 3. The indexes of prism II, however, were larger than those of prism I by $24 \times 10^{-6}$.

The corrected observed indexes, table 3 , for $20^{\circ}$ and $40^{\circ} \mathrm{C}$ were reduced to indexes at $30^{\circ} \mathrm{C}$ by means of the coefficients in table 2 , and the resulting indexes were averaged with the corrected observed values at $30^{\circ}$. The following four-constant Ketteler-Helm- 
TABLE 3. Observed index of refraction of magnesium oxide corrected to $20^{\circ}, 30^{\circ}$, and $40^{\circ} \mathrm{C}$

(A verage for two prisms)

\begin{tabular}{|c|c|c|c|}
\hline \multirow{2}{*}{ Wavelength } & $20^{\circ} \mathrm{C}$ & $30^{\circ} \mathrm{C}$ & $40^{\circ} \mathrm{C}$ \\
\cline { 1 - 2 }$A$ & & & \\
\cline { 1 - 2 } & & & \\
7679 & 1.728677 & 1.728805 & 1.728940 \\
7065 & 1.730977 & 1.731109 & 1.731272 \\
6678 & 1.732721 & 1.732871 & 1.733008 \\
6563 & 1.733299 & 1.733444 & 1.733592 \\
5893 & 1.737319 & 1.737485 & 1.737631 \\
5461 & 1.740729 & 1.740887 & 1.741044 \\
4861 & 1.747060 & 1.747233 & 1.747407 \\
4358 & 1.754652 & 1.754832 & 1.755010 \\
4047 & 1.760990 & 1.761174 & 1.761371 \\
& & & \\
& & & \\
& & &
\end{tabular}

holtz dispersion equation was fitted to the resulting averaged indexes:

$$
n^{2}=2.957019-0.0101373 \lambda^{2}+\frac{0.0216485}{\lambda^{2}-0.0158650} .
$$

In this equation the wavelength in microns is used.

The accuracy of fit of this equation is shown in table 4 , which lists the averaged corrected observed indexes, the indexes computed by the equation, and the differences.

TABLE 4. Comparison of indexes computed by equation (1) with observed values

All are for $30^{\circ} \mathrm{C}$.

\begin{tabular}{|c|c|c|c|}
\hline Wavelength & $\begin{array}{l}\text { A veraged } \\
\text { corrected } \\
\text { observed } \\
\text { index }\end{array}$ & $\begin{array}{l}\text { index com- } \\
\text { puted by } \\
\text { equation (1) }\end{array}$ & $\begin{array}{l}\text { Difference } \\
\text { observed } \\
\text { minus } \\
\text { computed }\end{array}$ \\
\hline $\begin{array}{c}4 \\
7679 \\
7065 \\
6678 \\
6563 \\
5893 \\
5461 \\
4861 \\
4358 \\
4047\end{array}$ & $\begin{array}{l}1.728810 \\
1.731119 \\
1.732866 \\
1.733445 \\
1.737478 \\
1.740886 \\
1.747233 \\
1.754830 \\
1.761178\end{array}$ & $\begin{array}{l}1.728807 \\
1.731113 \\
1.732867 \\
1.733447 \\
1.737478 \\
1.740883 \\
1.747232 \\
1.754836 \\
1.761178\end{array}$ & $\begin{array}{l}+3 \times 10^{-6} \\
+0 \\
-1 \\
-2 \\
0 \\
+3 \\
+1 \\
-6 \\
0\end{array}$ \\
\hline
\end{tabular}

With the computed indexes at $30^{\circ} \mathrm{C}$ and the temperature coefficients of table 2 it is possible to construct a table of indexes of refraction of magnesium oxide for various temperatures between $20^{\circ}$ and $40^{\circ} \mathrm{C}$ and for selected wavelengths between 4000 and $7800 \mathrm{~A}$. The computed values $20^{\circ}, 30^{\circ}$, and $40^{\circ} \mathrm{C}$ for the nine wavelengths actually used in the visual range and two others, at 5085 and 6438 a (cadmium lines). are listed in table 5 .

In table 5 the averaged values of the residuals observed minus computed at $20^{\circ}, 30^{\circ}$, and $40^{\circ} \mathrm{C}$. are $+1,0$, and $-1 \times 10^{-6}$, respectively; and at only 1 of the 27 observed points does the residual exceed $9 \times 10^{-6}$.

Seven of the wavelengths for which Strong and Brice measured the index of magnesium oxide are among those of table 5. For comparison with the results of Strong and Brice, we have computed the index for $23^{\circ} \mathrm{C}$, the temperature at which their measurements were made, using the $\Delta n$ 's of table 5 . These are tabulated, with those of Strong and Brice,
TABLE 5. Index of refraction of magnesium oxide at $20^{\circ}, 30^{\circ}$, and $40^{\circ} \mathrm{C}$, at 11 selected wavelengths

\begin{tabular}{|c|c|c|c|c|c|}
\hline \hline \multirow{2}{*}{ Wavelength } & $\begin{array}{c}\text { Index at- } \\
20^{\circ} \mathrm{C}\end{array}$ & $\Delta n$ & $\begin{array}{c}\text { Index at- } \\
30^{\circ} \mathrm{C}\end{array}$ & $\Delta n$ & $\begin{array}{c}\text { Index at- } \\
40^{\circ} \mathrm{C}\end{array}$ \\
\cline { 1 - 2 } $\mathrm{A}$ & & & & & \\
7679 & 1.728670 & 137 & 1.728807 & 139 & 1.728946 \\
7065 & 1.730971 & 142 & 1.731113 & 144 & 1.731257 \\
6678 & 1.732722 & 145 & 1.732867 & 147 & 1.733014 \\
6563 & 1.733301 & 146 & 1.733447 & 148 & 1.733595 \\
6438 & 1.733956 & 148 & 1.734104 & 150 & 1.734254 \\
5893 & 1.737324 & 154 & 1.737478 & 156 & 1.737634 \\
5461 & 1.740723 & 160 & 1.740883 & 162 & 1.741045 \\
5085 & 1.744415 & 165 & 1.744580 & 167 & 1.744747 \\
4861 & 1.747062 & 170 & 1.747232 & 172 & 1.747404 \\
4358 & 1.754655 & 181 & 1.754836 & 183 & 1.755019 \\
4047 & 1.760988 & 190 & 1.761178 & 192 & 1.761370 \\
\hline Abbe number, $\nu$ & 53.58 & $-\ldots$ & 53.50 & $-\ldots$ & 53.52 \\
\hline
\end{tabular}

in table 6. For further comparison, the differences, the average of the differences, second differences, and the average of the second differences are shown. These appear to show a systematic difference of index of $37 \times 10^{-5}$ between the samples measured by Strong and Brice and those reported here.

TABLE 6. Comparison of National Bureau of Standards indexes with those of Strong and Brice for magnesium oxide

\begin{tabular}{|c|c|c|c|c|}
\hline Wavelength & $\operatorname{NBS} \stackrel{n}{\left(23^{\circ} \mathrm{C}\right)}$ & $\begin{array}{c}n \\
\text { Strong and } \\
\text { Brice }\left(23^{\circ} C\right)\end{array}$ & Difference & $\begin{array}{c}\text { Second } \\
\text { difference }\end{array}$ \\
\hline $\begin{array}{c}A \\
4047 \\
4358 \\
4861 \\
5461 \\
5893 \\
6563 \\
7065\end{array}$ & $\begin{array}{l}1.761045 \\
1.754709 \\
1.747113 \\
1.740771 \\
1.737370 \\
1.733345 \\
1.731014\end{array}$ & $\begin{array}{l}1.76137 \\
1.75510 \\
1.74744 \\
1.74122 \\
1.73789 \\
1.73364 \\
1.73127\end{array}$ & $\begin{array}{l}32 \times 10^{-5} \\
39 \\
33 \\
45 \\
52 \\
29 \\
26\end{array}$ & $\begin{array}{l}-5 \times 10^{-5} \\
+2 \\
-4 \\
+8 \\
+15 \\
-8 \\
-11\end{array}$ \\
\hline & & A verage & 37 & 8 \\
\hline
\end{tabular}

Strong and Brice also measured the index of magnesium oxide at $2^{\circ} \mathrm{C}$ for two wavelengths, 6563 and $4861 \mathrm{~A}$. 'The resulting thermal coefficients for the $2^{\circ}$ to $23^{\circ} \mathrm{C}$ range were $1.14 \times 10^{-5}$ and $1.47 \times 10^{-5}$, respectively, compared to $1.46 \times 10^{-5}$ and $1.70 \times 10^{-5}$, respectively, obtained in the present work for the $20^{\circ}$ to $30^{\circ} \mathrm{C}$ range; and $1.48 \times 10^{-5}$ and $1.72 \times 10^{-5}$ for the $30^{\circ}$ to $40^{\circ} \mathrm{C}$ range. Although our results show that the thermal coefficient increases with temperature the rate is insufficient to account for the difference between these coefficients and those of Strong and Brice.

The Abbe numbers obtained by Strong and Brice, 53.80 at $2^{\circ} \mathrm{C}$ and 53.55 at $23^{\circ}$, compare favorably with those reported here.

\section{Measurements in the Infrared and Ultra- violet Range}

The indexes in the infrared and ultraviolet regions were measured by the minimum-deviation method. The minimum deviation was measured in a Zeiss spectrometer of the Wadsworth type with concave mirrors for collimating and collecting. These mirrors are of off-axis portions of paraboloids and their figure is such that their definition and resolving power are 


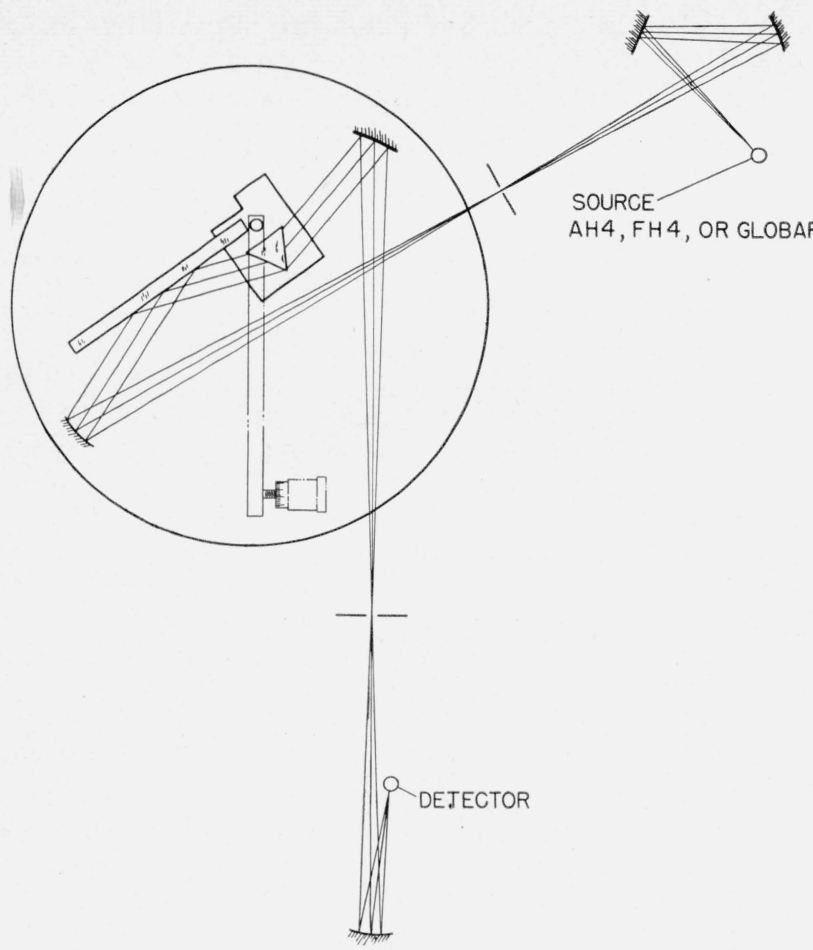

Figure 1. Schematic drawing of infrared spectrometer with source and detector.

excellent. The prism table and Wadsworth mirror are rotated by means of a lever and a tangent screw, the position of the screw being indicated by a longitudinal scale and divided head. The instrument and accessories are shown schematically in figure 1 .

The angular position of the prism table has been expressed as a function of scale reading by means of a collimator, a telescope, and two small plane mirrors mounted together, with a small angle between them. This angle was stepped off repeatedly until the entire scale had been covered. From the data so obtained a table of corrections was made. These corrections were plotted on a graph, and the corrections used were read from a smooth curve fitted to the plotted points. The calibration was carried to the nearest second of angle.

The minimum deviations of prisms I and II were too small to be used in the Zeiss spectrometer, and the combination of both prisms gave deviations that were too large. Consequently, the angle of prism I was reduced by grinding and polishing. At the same time, prism II, which had become dull, was resurfaced. These two were then mounted together on a base plate forming a composite prism with an effective angle of $49^{\circ} 59^{\prime} 34^{\prime \prime}$.

For the ultraviolet and the infrared to $2.4 \mu$ a lead sulfide photoconducting cell was used as the detector. For longer wavelengths, a Golay pneumatic detector was used. The responses were amplified (the Golay amplifier and chopper were used with both detectors) and indicated or recorded by an electronic selfbalancing potentiometer. A synchronous motor with

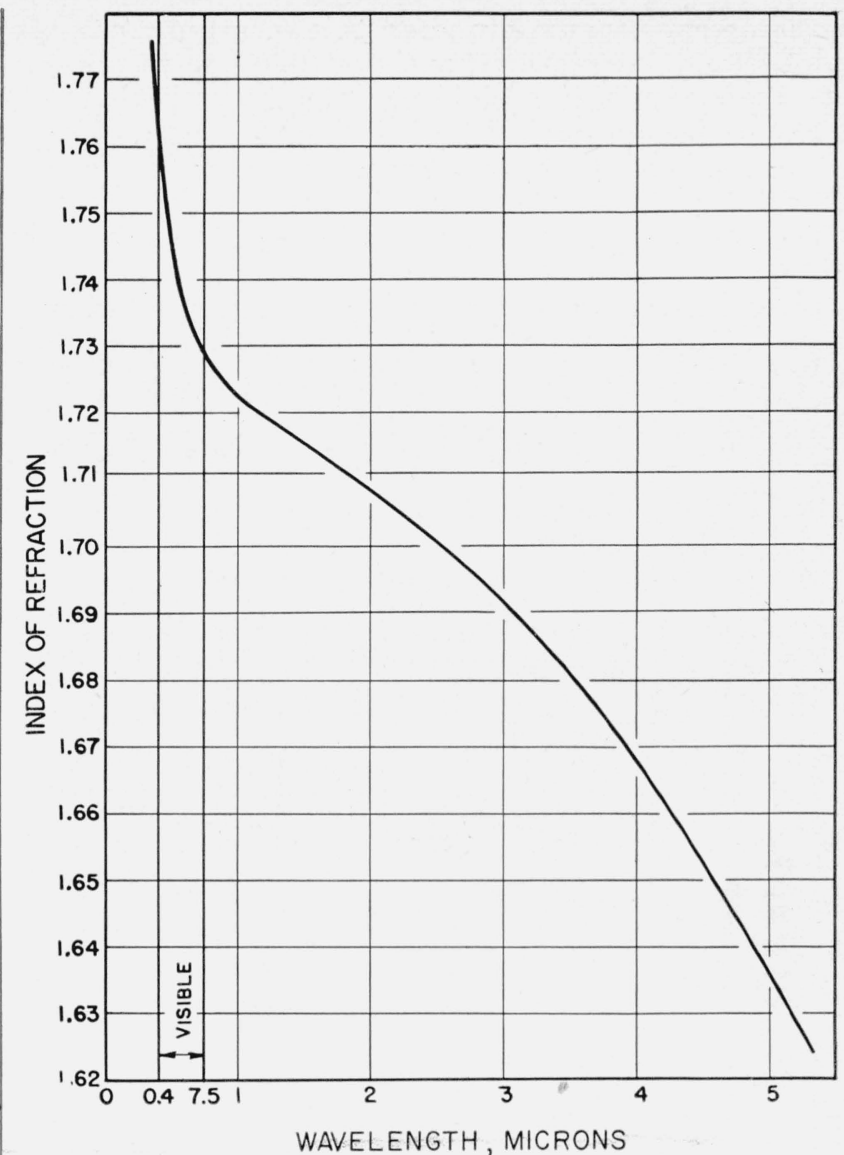

FIGURE 2. Index of refraction of magnesium oxide at $23.3^{\circ} \mathrm{C}$.

suitable gears was used to drive the spectrometer screw. As the chart in the potentiometer was also driven by a synchronous motor, the resulting chart gave response as a function of spectrometer position. The exploratory work by means of which the spectrum lines and absorption bands were identified and their approximate scale readings located was done by means of these charts. The scale readings corresponding to the peaks of absorption by which the five longest wavelengths were identified were read from the charts. However, hand settings for maximum response on the emission lines of the spectrum of mercury were made repeatedly, and the results were averaged to obtain higher precision.

The prism was placed upon the spectrometer table, leveled by placing shims under one corner, and turned by hand to the position of minimum deviation. A visible spectrum line was used for the adjustment. After these adjustments had been made, the physical detector was put in place to receive the flux from the exit slit.

With the spectrometer used it was not possible to observe the undeviated beam, consequently the angle of minimum deviation could not be measured directly. For flux to reach the exit slit, it must have been deviated between $37^{\circ}$ and $57^{\circ}$. The difference in minimum deviation between an invisible line and 
a visible one was measured on this spectrometer and added to the deviation for the visible line to obtain the angle of minimum deviation for the invisible line. The minimum deviation for the visible line was measured with high accuracy on another spectrometer by visual means. Several visible lines were used and the results averaged to obtain better accuracy.

The indexes resulting from these measurements are presented in table 7 . These data are also presented graphically in figure 2 .

TABLE 7. Index of refraction of magnesium oxide for wavelengths in the infrared and ultraviolet at $23.3^{\circ} \mathrm{C}$

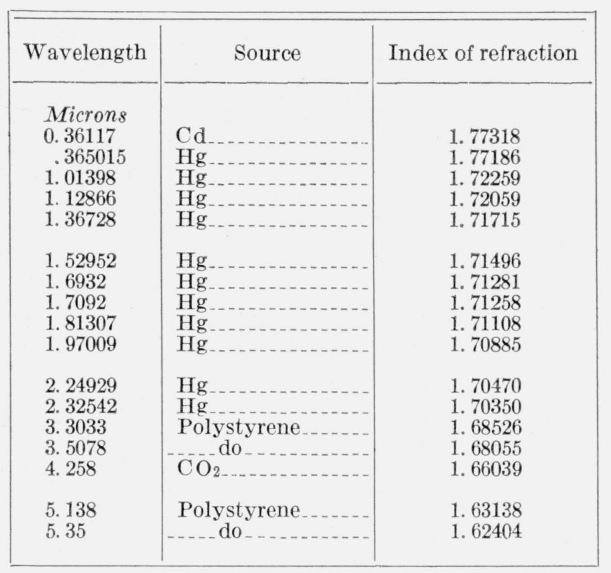

Several four- and five-constant equations have been fitted to the data for the entire wavelength range. The best is the following five-constant one, which was fitted by least squares:

$$
\begin{aligned}
n^{2}= & 2.956362-0.01062387 \lambda^{2}-0.0000204968 \lambda^{4}+ \\
& \frac{0.02195770}{\lambda^{2}-0.01428322},
\end{aligned}
$$

where $\lambda$ is in microns. Admittedly the fit is not excellent. In particular, in the visible region, where the observed indexes are probably accurate within a few units in the sixth decimal place, the values computed by this formula differ systematically from those computed with eq (1) by as much as $\pm 5 \times 10^{-5}$. In general, however, considering the whole range of wavelength, it is probable that no further improvement of eq (2) is justified because the indexes in the ultraviolet and infrared are less accurately determined than those in the visible region. Although the indexes for the sharp emission lines of cadmium and mercury are probably accurate to a few units in the fifth decimal place, some of those identified by means of the relatively broad absorption bands of polystyrene and carbon dioxide may be inaccurate in the fourth decimal place.

Washington, July 14, 1952. 